\title{
Type 2 Diabetes and Testosterone Therapy
}

\author{
Geoffrey Hackett ${ }^{\circledR}$ \\ Department of Urology, Good Hope Hospital, Heart of England Foundation Trust and University of Aston, Birmingham, UK
}

\begin{abstract}
A third of men with type 2 diabetes (T2DM) have hypogonadotrophic hypogonadism $(\mathrm{HH})$ and associated increased risk of cardiovascular and all-cause mortality. Men with $\mathrm{HH}$ are at increased risk of developing incident T2DM. We conducted MEDLINE, EMBASE, and COCHRANE reviews on T2DM, $\mathrm{HH}$, testosterone deficiency, cardiovascular and all-cause mortality from May 2005 to October 2017, yielding 1,714 articles, 52 clinical trials and 32 randomized controlled trials (RCT). Studies with testosterone therapy suggest significant benefits in sexual function, quality of life, glycaemic control, anaemia, bone density, fat, and lean muscle mass. Meta-analyses of RCT, rather than providing clarification, have further confused the issue by including under-powered studies of inadequate duration, multiple regimes, some discontinued, and inbuilt bias in terms of studies included or excluded from analysis.
\end{abstract}

Keywords: Cardiovascular diseases; Diabetes mellitus, type 2; Hypogonadism; Major adverse coronary events; Testosterone deficiency

This is an Open Access article distributed under the terms of the Creative Commons Attribution Non-Commercial License (http://creativecommons.org/licenses/by-nc/4.0) which permits unrestricted non-commercial use, distribution, and reproduction in any medium, provided the original work is properly cited.

\section{INTRODUCTION}

Type 2 diabetes (T2DM) is a major health and economic concern for the Western World. In the UK in $2017,26 \%$ of the population over 65 years are diagnosed, and $56 \%$ of these are men. The prevalence is 6 times greater in men of South East Asian origin and 3 times greater in men of Afro-Caribbean background [1]. In the USA, two-thirds of men over 65 years have T2DM [2].

Obesity is the most potent risk factor for T2DM. It accounts for $80 \%$ to $85 \%$ of the overall risk of developing T2DM and underlies the current global spread of the condition [1]. Other risk factors are lack of exercise, family history, and gestational diabetes. In men, there is now strong evidence linking low testosterone to obesity, T2DM and components of the metabolic syndrome [1]. Several studies have shown high levels of hypogonadism (HG) in men with T2DM with around $20 \%$ being overtly hypogonadal with total testosterone (TT) below $8 \mathrm{nmol} / \mathrm{L}$ and around 50\% falling below the $12 \mathrm{nmol} / \mathrm{L}$ level for mild HG [3]. In 2015, the American Association of Clinical Endocrinologists recommended that all men with T2DM should be screened for HG along with all men with body mass index (BMI) $>30$ $\mathrm{kg} / \mathrm{m}^{2}$ or waist circumference over $104 \mathrm{~cm}$ [4]. The 2018 Endocrine Society guidelines, in contrast, continues to advise against any form of testosterone screening. Recent re-classification of HG by the Endocrine Society refers to T2DM related HG as 'functional' and some endocrine guidelines [5] suggest that only 'classical' HG be treated, despite no published studies demonstrating 
that this group responds better. On the contrary, evidence suggests that men classified as 'functional HG' form the majority of patients showing benefit from clinical trials [6].

\section{LOW TESTOSTERONE AND INCIDENT TYPE 2 DIABETES}

The link between T2DM and HG is considered bidirectional and conventional management has recovered around lifestyle strategies of weight and exercise which are clearly failing as the prevalence continues to increase [7]. The evidence suggests that low testosterone leads to new onset T2DM and contributes to worsening comorbidities [8-10].

In a study of 1,413 men, those in the first (lowest) tertile of low free testosterone (FT) and TT were four times more likely to have diabetes than those in the third tertile of low TT and FT [8]. Furthermore, low FT and sex hormone binding globulin (SHBG) have been shown to predict the onset of diabetes in men in up to 10 years of follow-up (odds ratio [OR], 1.58 for a decrease of $4 \mathrm{ng} / \mathrm{dL} \mathrm{FT}$ and OR, 1.89 for a decrease of $16 \mathrm{nmol} / \mathrm{L} \mathrm{SHBG)} \mathrm{[9].} \mathrm{A} \mathrm{meta-analysis} \mathrm{of} \mathrm{prospective}$ studies, showed men with TT levels above $15.5 \mathrm{nmol} / \mathrm{L}$ had a $42 \%$ lower risk of incident diabetes (relative risk, 0.58; 95\% confidence interval [CI], 0.39 to 0.87 ) compared with men with a TT of no greater than $15.5 \mathrm{nmol} / \mathrm{L}[11]$. In a 2011 meta-analysis Corona et al's study [11], found baseline TT was $2.08 \mathrm{nmol} / \mathrm{L}$ (95\% CI, 3.57 to 0.59 ) lower in men who developed incident T2DM compared with those who did not. A major reason for this diminished relationship in some studies was adjustment for central fat by waist circumference. In addition, individual studies lacked power because only of the low rates of incident diabetes.

Several longitudinal studies have shown that low levels of TT and FT independently predict the later development of T2DM or metabolic syndrome [12-18].

In the largest study to date, Holmboe et al [19] reported on 5,250 men from the Danish population followed-up for 29 years and showed that low TT and low SHBG were strongly associated with incident T2DM. There were 35/599 (lowest quartile of TT) vs. 13/599 (highest quartile of $\mathrm{TT})(\mathrm{p}=0.13)$ in the non-smokers, corresponding values were $48 / 660$ vs. $17 / 658(\mathrm{p}=0.034)$. As there was no effect of luteinizing hormone, the authors concluded that 'primary hypogonadism' was not a risk 'factor' for T2DM but that low TT should be considered a risk 'marker' for T2DM. As there were no data on testosterone therapy reported by Holmboe et al [19], a causal relationship could not be established.

\section{LOW TESTOSTERONE AND INCREASED CARDIOVASCULAR AND ALL-CAUSE MORTALITY}

Numerous long-term studies, and various reviews and meta-analyses, have provided evidence to support the association between testosterone deficiency (TD) and increased cardiovascular (CV) and all-cause mortality [20-25], although evidence for a pathogenic link is lacking [26,27].

A systematic review and meta-analysis evaluating the association between endogenous testosterone and mortality concluded that low levels of endogenous testosterone are associated with an increased risk of all-cause and CV death in community-based studies of men, with a reduction of 2.1 standard deviations in TT being associated with a $25 \%$ increase in mortality. However, most of the studies had issues with cohort selection and choice [20,21].

Two systematic reviews and meta-analyses evaluating the association between endogenous testosterone and all-cause mortality and cardiovascular disease (CVD) mortality [20] reported a protective effect of increased TT. Research examining the data from 1,954 subjects, in terms of several statistical models, found that even after strict adjustment for comorbidities, there was a consistent link between testosterone level and mortality risk throughout, without proving causation [28].

In a prospective study involving 581 men with T2DM, patients were followed-up for a mean of 5.81 years. Low testosterone was defined as TT<10.4 nmol/L. Fifty-one men received testosterone therapy for at least 2 years. The mortality rates were $20 \%$ in the low testosterone group vs. $9.1 \%$ in the normal testosterone group, independent of comorbidities and therapies, and 9.4\% in those with TD in the treated group [23].

In a 10-year Australian study involving 3,690 older men, TT and FT levels in the normal range were associated with reduced all-cause and CV mortality. This was the first evidence to suggest that that both low and high levels are associated with all-cause mortality, and higher levels of dihydrotestosterone (DHT) reduce 
CV risk [24].

A Swedish study involving 1,109 subjects aged 40 years and over, with a mean follow-up of 14.1 years, suggested a strong association between low baseline testosterone and incident myocardial infarction (MI) [25].

Although these studies demonstrated a consistent association between low testosterone and CVD incidence and mortality, this did not prove a pathogenic link. However, the conclusions from a review on testosterone and mortality were that low testosterone could be a 'marker' of illness [27,28].

\section{METABOLIC EFFECTS OF TESTOSTERONE THERAPY IN TYPE 2 DIABETES}

Low testosterone has been demonstrated to be closely linked with components of the metabolic syndrome in T2DM [11]. The mainstay of modern therapy for T2DM is directed to the reduction of CV risk. Smoking cessation, reduction and exercise have been shown to improve insulin sensitivity and should always be offered in conjunction with other therapies [29]. Aggressive management of dyslipidaemia and hypertension had led to National Institute for Health and Care Excellence (NICE) guidance that all men with T2DM being offered metformin, statin, and angiotensin-converting enzyme inhibitor at initial diagnosis in all patients with T2DM unless contraindicated [29].

\section{THE IMPORTANCE OF GLYCAEMIC CONTROL}

The main target to improve outcome in T2DM has traditionally been improved glycaemic control as assessed by $\mathrm{HbA1c}$ or more recently by International Federation of Clinical Chemistry and Laboratory Medicine [29]. Insulin resistance, as measured by the Homeostatic Measurement of insulin resistance (HOMAIR) is known to be an independent risk factor for CV events [30] and the gold standard for assessment of change in insulin resistance. Bonora et al [30] reported that each unit change in HOMA-IR was associated with a $50 \%$ increase in CV events. In the UK Prospective Diabetes Study trial, each 1\% increase in HbA1c was associated with a $21 \%$ increase in death, $14 \%$ increase in $\mathrm{MI}$ and $43 \%$ increase in peripheral vascular disease [31]. Intensive management with metformin $v s$. conventions management was shown to reduce $\mathrm{HbA1c}$ from a mean of $7 \%$ at baseline to $6.2 \%$ at 12 months, but long-term follow-up over 10 years plus have shown that $\mathrm{Hb1c}$ levels rises with time and that weight loss is not maintained [32]. We therefore need alternative strategies as eventually many patients fail with a regime dedicated to lifestyle change and hypoglycaemic drugs.

\section{TESTOSTERONE THERAPY AND GLYCAEMIC AND METABOLIC CONTROL}

Prospective, observational studies show that visceral adiposity, smoking and the metabolic syndrome predict the development of low testosterone levels [33,34]. Large prospective USA cohort studies [35] and in Germany [36] men showed that weight gain and development of diabetes or the metabolic syndrome accelerated the age-related decline in testosterone. In men with T2DM followed longitudinally, changes in testosterone levels over time correlated inversely with changes in insulin resistance, suggesting that improved lifestyle factors or altered pharmacological management that improved insulin sensitivity may also contribute to increased testosterone levels [37]. Observational studies found that both weight loss and exercise increase testosterone levels [38]. Bariatric surgery improves glycaemic control and testosterone levels but there are clearly implications of cost and the selection of appropriate patients [38].

Early trials in obese men without T2DM yielded variable results. However, a 4.3-year follow-up from European Male Ageing Study [39] found that biochemical reversal of secondary HG was not associated with improvement in symptoms. And a placebo controlled randomized controlled trial ( $\mathrm{RCT}$ ) in obese hypogonadal men treated with severe weight reduction and either long acting testosterone undecanoate (TU) injections or placebo for 12 months, found that although weight and BMI loss was achieved in both groups, only the TU group preserved lean muscle and achieved symptomatic benefit [40,41]. This study provides strong evidence for the benefits of testosterone therapy for longer than 6 months combined with life-style for men with HG and metabolic syndrome (Fig. 1).

A large-scale study in the Australia, the T4D study 
is due to report on the possible reduction of incident diabetes by treating younger obese men with metabolic syndrome with TU [42].

In a small study of 24 patients, Kapoor et al [43] found that Testosterone Enanthate every 2 weeks for 12 weeks lowered HOMA-IR by 1.7 units and HbA1c by $0.37 \%$, with slight reduction in total cholesterol.

The Moscow study involved 184 obese men randomised to long acting TU for 26 weeks found marked reductions in weight, BMI, waist circumference, and inflammatory markers but no reduction in fasting glucose [44].

The TIMES2 study involved 220 men with either T2DM or metabolic syndrome treated for 26 weeks

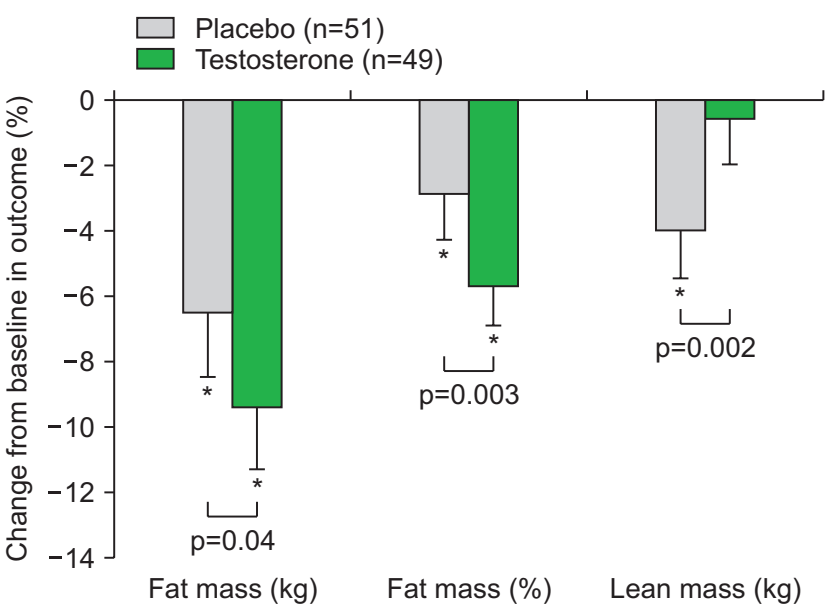

${ }^{*} \mathrm{p}<0.05$ vs. baseline within group; data are mean $+95 \%$ confidence interval

Fig. 1. Changes from baseline in body composition after 56 weeks treatment with intramuscular testosterone undecanoate (plus intense exercise) or placebo (plus intensive exercise). Data from $\mathrm{Ng}$ Tang Fui et al (BMC Med 2016;14:153) [41].

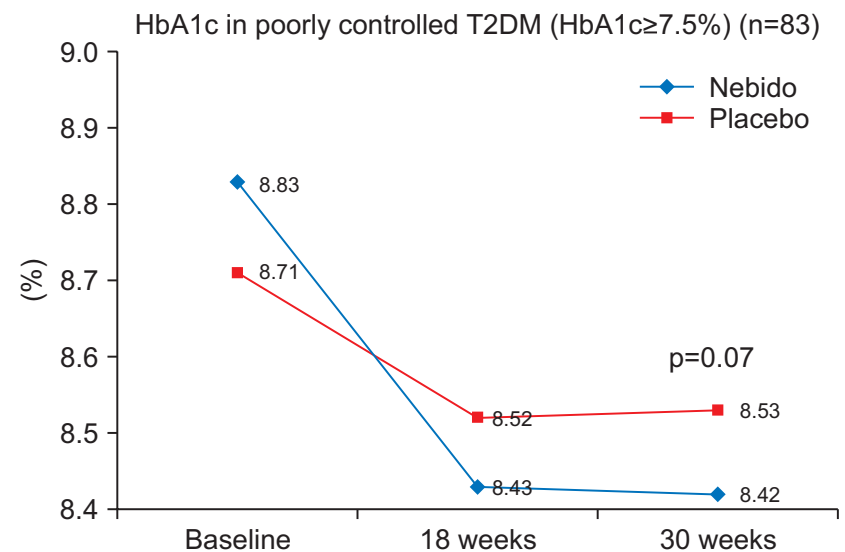

with $2 \%$ testosterone gel followed by an open label phase. There was a significant reduction in HOMA-IR at 12 months $(\mathrm{p}=0.006)$ but although the HbA1c fell by $0.4 \%$ at 12 months, in men with T2DM, this just failed to reach significance. As the randomisation phase lasted only 6 months, there was possible selection bias for those men continuing to the open label phase and the drop-out rate was rather high at $29 \%$ [45].

The largest RCT conducted to date exclusively in men with T2DM is the BLAST study (an acronym of the towns and cities involved-Birmingham, Lichfield, Tamworth, Atherstone and Sutton Coldfield). This involved 857 men screened from 7 UK general practice diabetes registers to provide 199 men detected with $\mathrm{TT}<12 \mathrm{nmol} / \mathrm{L}$ or $\mathrm{FT}<0.25 \mathrm{nmol} / \mathrm{L}$ (mild HG group) or $\mathrm{TT}<8 \mathrm{nmol} / \mathrm{L}$ or $\mathrm{FT}<0.18 \mathrm{nmol} / \mathrm{L}$ (severe HG) group. Men were randomised to TU 1,000 mg or placebo injections, initially after 6 weeks and then 12 weeks for a 30 weeks intervention period [38]. There was a significant treatment effect in $\mathrm{HbA1c}$ in the poorly controlled men $(\mathrm{HbA} 1 \mathrm{c} \geq 7.5 \%)$ of $0.4 \%$ at 30 weeks and a significant effect in the well-controlled $(<7.5 \%)$ at 18 weeks $(\mathrm{p}=0.002)$ but not at 30 weeks. A likely explanation for this was the impact of diet and lifestyle advice given at baseline for all patients and the likelihood that the additional impact was this was diminished by 30 weeks. There were significant reductions in weight, BMI, and waist circumference, plus marked improvement in sexual function and quality of life scores. These parameters continued to improve in the 12 months open label phase. HOMA-IR was unchanged during the 30-week RCT but fell by 1.5 units in the 12 months open label phase, along with marked falls in insulin levels in the

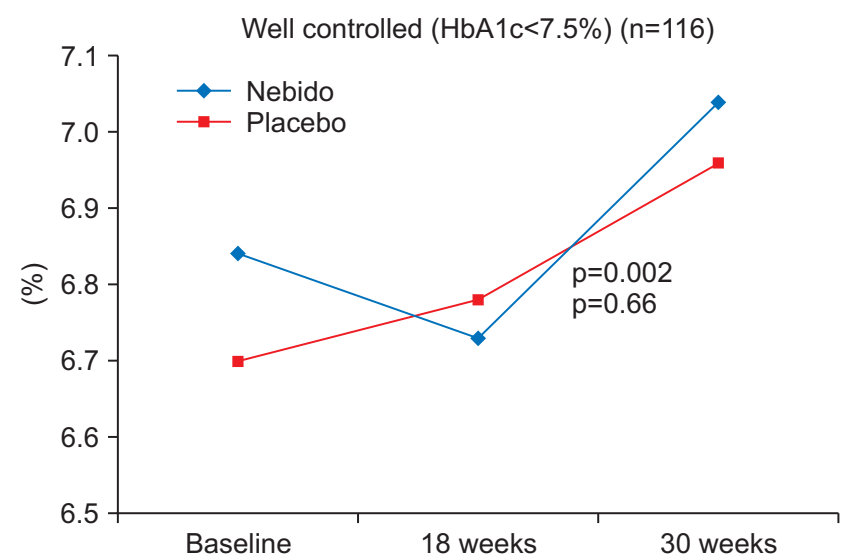

Fig. 2. Changes in $\mathrm{HbA1c}$ from baseline with 30 weeks double blind therapy with intramuscular testosterone undecanoate or placebo in poorly controlled type 2 diabetes (T2DM) $(\mathrm{HbA} 1 \mathrm{c}=$ or $>7.5 \%)$ vs. well controlled (HbA1c<7.5\%). Data from Hackett et al (Int J Clin Pract 2014;68:203-15) [46]. 
open label phase. Once again, interpreting data from the 106 patients in the open label phases must consider selection bias, as analysis showed that the decisions to proceed to the open label phase was driven by improvements in sexual function (Fig. 2) [46].

Dhindsa et al [47] studied 94 men with T2DM, 50 eugonadal and 44 with hypogonadotrophic hypogonadism $(\mathrm{HH})$, randomised to either testosterone cypionate $250 \mathrm{mg}$ every 2 weeks or placebo injection for 24 weeks. Men with $\mathrm{HH}$ had higher subcutaneous and visceral fat mass than eugonadal men. Insulin sensitivity measured by glucose infusion rate (GIR) was 36\% lower in men with HH. GIR increased by $32 \%$ after 24 weeks of testosterone therapy but did not change after placebo ( $p=0.03$ for comparison). HOMA-IR improved by $1.4 \%$ in the treatment $(\mathrm{p}=0.03)$ and was unchanged with placebo. There was a decrease in subcutaneous fat mass (23.3 $\mathrm{kg})$ and increase in lean mass $(3.4 \mathrm{~kg})$ after testosterone treatment $(p<0.01)$ compared with placebo. Visceral and hepatic fat did not change. The expression of insulin signalling genes (IR-b, IRS-1, AKT-2, and GLUT4) in adipose tissue was significantly lower in men with $\mathrm{HH}$ and was up-regulated after testosterone treatment. Testosterone treatment also caused a significant fall in circulating concentrations of free fatty acids, C-reactive protein, interleukin-1 $\beta$, tumour necrosis factor- $\alpha$, and leptin ( $\mathrm{p}<0.05$ for all).

A 5-year study of 40 obese hypogonadal men, 20 treated with TU and 20 randomised to control, showed reductions in weigh $(15 \%)$, waist circumference $(10 \mathrm{~cm})$, and $\mathrm{HbA1c}(1.5 \%)$, and 2.15-point reduction in HOMAIR [48].

Long term registry studies have shown reductions in weight, BMI, waist circumference, and $\mathrm{HbA1c}$ maintained for up to eight years [49,50].

Gianatti et al [51] conducted a 40-week study of TU vs. Placebo in 88 obese men with T2DM (mean age, 62 years) and concluded that there was no significant impact on HOMA-IR or HbA1c but there was a reduction in fat mass and increase in lean muscle mass. However, the treatment group were notably less obese (93 kg vs. $101.5 \mathrm{~kg}$ ) with baseline HOMA-IR of 2.1 falling to 1.75 $(p=0.08)$. Baseline HbA1c was $6.8 \%$. This suggests that patients were well controlled with minimal insulin resistance suggesting that the study might have been under-powered for this cohort.

\section{TESTOSTERONE AND SEXUAL FUNCTION IN TYPE 2 DIABETES}

Men with T2DM have erectile dysfunction (ED) due to multiple comorbidities, most notably macro- and micro-vascular disease, autonomic and peripheral neuropathy, depression, and multiple medications in addition to HG [52]. Zitzmann et al [49,53] found that falling testosterone levels significantly impact on ED around $8 \mathrm{nmol} / \mathrm{L}$ and Buvat et al [54] described a threshold of $10.4 \mathrm{nmol} / \mathrm{L}$ where testosterone therapy might salvage men who fail with phosphodiesterase type 5 (PDE5) inhibitors. Men with T2DM also have significantly reduced responses to conventional ED therapy, due to multiple comorbidities [55]. Hackett et al [3,56] screened a UK population of men with T2DM and found that the impact of $\mathrm{HG}$ on $\mathrm{ED}$ was greatest in men with TT below $8 \mathrm{nmol} / \mathrm{L}$, in agreement with the findings of Zitzmann et al [53]. These findings suggest that there are pitfalls in drawing conclusions from studies of testosterone therapy where men with T2DM form only a minor subgroup. Correcting the low testosterone levels will usually only address the ED burden due to HG but still leave the impact due to other comorbidities [56], which will need to be addressed by additional specific therapies [56]. Some trials only evaluated ED using international index of erectile function-5 (IIEF-5), which only evaluates erections, whereas testosterone is involved in desire, sexual frequency, orgasm, ejaculation, sensation, and sexual satisfaction [57].

The BLAST study [57], involving 199 men (mean age, 61 years) with T2DM treated with TU, 1,000 mg for 30 weeks with 12-month open label follow-up. Based on the finding from population screening and Zitzmann et al [53], this study evaluated men in the mild HG (8-12 nmol/L) and severe HG (below $8 \mathrm{nmol} / \mathrm{L}$ ) and found that the improvement in the severe group at 30 weeks was 3.9 points (5.8 points vs. placebo) (Fig. 3 ), equated to the difference between the groups at baseline screening, suggesting that this was correcting the disease burden due to HG. Improvements reached highest significance at 6 months, suggesting that studies of less than 6 months were of insufficient duration. In the sub-group of men taking a PDE5 inhibitor, the improvement at the end of the open label phase was 9.5 points in IIEF-EF, stressing the important of treating the multiple comorbidities. In the mild HG group, there was no improvement in IIEF-EF score, vs. pla- 

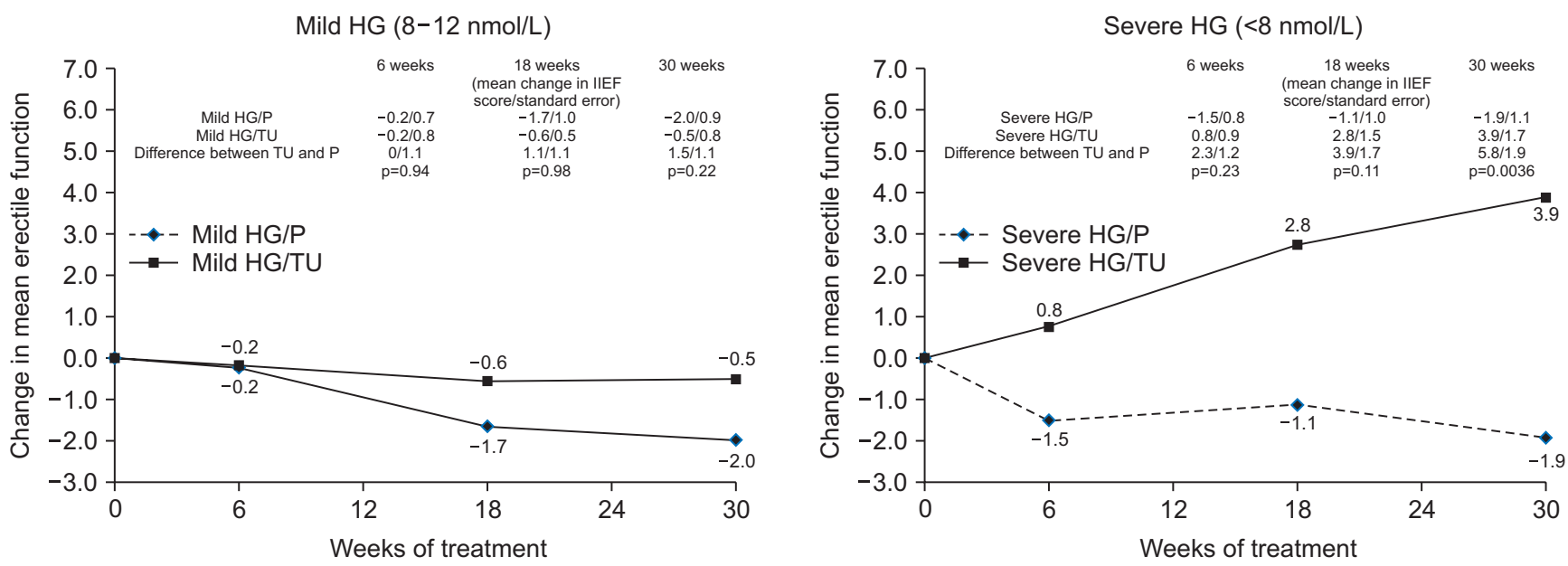

Fig. 3. Changes in international index of erectile function (IIEF) from baseline with 30 weeks double blind therapy with intramuscular testosterone undecanoate (TU) or placebo (P) in men with type 2 diabetes and mild hypogonadism (HG) $(8-12 \mathrm{nmol} / \mathrm{L})$ or severe $\mathrm{HG}(<8 \mathrm{nmol} / \mathrm{L})$. Data from Hackett et al (Int J Clin Pract 2014;68:203-15) [46].

cebo. There were brisk improvements in sexual desire in both groups, most marked in the severe group and prompt improvement in desire predicted later improvement in IIEF-EF. Men with depression, $23 \%$ of the group, showed little response by 30 weeks [50], which is in line with other studies looking at multiple parameters in T2DM where therapeutic responses were strong influenced by depression [57]. Meta-analyses have shown depression to be strongly linked with sexual dysfunction in T2DM, yet the impact has been largely ignored [58].

The TIMES-2 study [45] involved 12 months RCT of $2 \%$ testosterone gel in 220 men (mean age, 59 years) with either T2DM (62\%) or metabolic syndrome with a 4.87-point improvement in IIEF-EF score from a baseline of 12 points. Unfortunately, the drop-out rate was $29 \%$ which might reflect an issue related to gel, whereas BLAST involved injections administered by the nurse involved in the patient's normal diabetes care.

In the testosterone trials [59], involving older mean (mean age, 72 years) 37\% of 780 recruited patients had T2DM. The IIEF-EF score increased by 2.64 points $v s$. placebo, but sexual activity increased to 4 times per week, along with significant increase in sexual desire. The authors described this improvement as 'modest'. The disproportionate increase in desire and sexual activity in proportion to EF scores is probably related to age associated comorbidities as shown by the high coronary atheroma burden in the CV arm of the study. The authors concluded that PDE5 inhibitors might have produced a greater effect than testosterone therapy, quoting Spitzer et al [60]. They might, however have underestimated the benefits of increased sexual activity and desire in the context of the relationship of the couple. It is unlikely that PDE5 inhibitors alone would have been effective in this group, without the benefits in sexual desire associated with testosterone therapy in men with levels below $8 \mathrm{nmol} / \mathrm{L}$ [56]. Patients with HG were excluded from the regulatory trials of PDE5 inhibitors such that it is inappropriate to extrapolate response rates from studies in the eugonadal population [55]. The evidence suggests that older men with T2DM need a PDE5 inhibitor plus normalisation of testosterone levels [55,61]. The study by Spitzer et al [60] involved a population who had an excellent response to pre-treatment with sildenafil with an increase of over $3 \mathrm{nmol} / \mathrm{L}$ from baseline, such that the mean TT at randomisation to testosterone therapy was $12.63 \mathrm{nmol} / \mathrm{L}$ (up from 8.61 at baseline) meaning that 50\% did not fit their criteria for HG and therefore would not expect to benefit from testosterone therapy. Despite these weaknesses, the effect of testosterone replacement therapy (TRT) was close to significance, even though the exposure to testosterone was only 3 months. Paradoxically, despite recognising the effect of PDE5 inhibitors in the Spitzer study, only 1 of the long term longitudinal studies of testosterone included data on PDE5 inhibitor use, reporting a $12 \%$ use at baseline, increasing to $50 \%$ in 4 years of follow-up in the men taking testosterone [62]. 


\section{META-ANALYSES}

Several meta-analyses have considered the impact of testosterone therapy on metabolism but, far from clarifying the issue, in some cases they create confusion [63]. The highest level of evidence comes from RCTs, but many are of insufficient duration, often less than 26 seeks and sometimes only 12 weeks (mean, 33.5 weeks) [64]. Many involve mixed populations such that it is doubtful that changes in insulin resistance or HbA1c can be achieved in men without significant insulin resistance $[64,65]$. These analyses are likely to be of insufficient duration to answer questions as to CV safety of major adverse coronary events (MACE) [65]. Many studies on this subject exclude the first 6 months on the basis that events in this period are likely to be due to the untreated condition rather than the impact of therapy [23]. Different therapies are analysed together, often patches, oral medication, or implants that are largely obsolete or withdrawn [66]. Injections of different esters are grouped together, and USA studies do not include long acting TU, a major therapy in Europe for over a decade $[56,66]$. The inclusion of longitudinal studies creates bias related to inaccurate initial diagnosis, lack of follow-up diagnosis and little evidence of therapy compliance [65]. Recent evidence suggests a potential CV benefit from taking PDE5 inhibitors, often co-prescribe with testosterone therapy and this is also likely to be associated with men in stable long-term relationships associated with health and socio-economic benefits [67]. Many longitudinal studies have failed to address these issues $[68,69]$. The inclusion or exclusion of a small number of controversial studies can profoundly alter the conclusions [68,70].

In contrast a comprehensive meta-analysis of 156 RCTS by Huo et al [68] concluded that there the prescription of testosterone supplementation for low-T for CV health, sexual function, physical function, mood, or cognitive function is without support from RCT. There was no analysis of data related to insulin resistance and no attempt to conduct a sub-analysis of men with cardiometabolic disease. PDE5 inhibitor use was not recorded.

A recent meta-analysis by Ponce et al [69] concluded that testosterone therapy improved sexual desire, ED, sexual satisfaction but increased erythrocytosis. A meta-analysis by Corona et al [70] involving 59 RCTs involving 3,029 treated and 2,049 controls concluded that there was clear evidence that TRT reduced fat mass and increased lean muscle mass (Fig. 4). They also concluded that TRT improved insulin resistance and glycaemic control with results being more marked in me with metabolic disease [70]. There were non-significant effects on lipids or blood pressure. The same group also concluded that TRT improved sexual desire and erectile function [65] and that there was no suggestion of

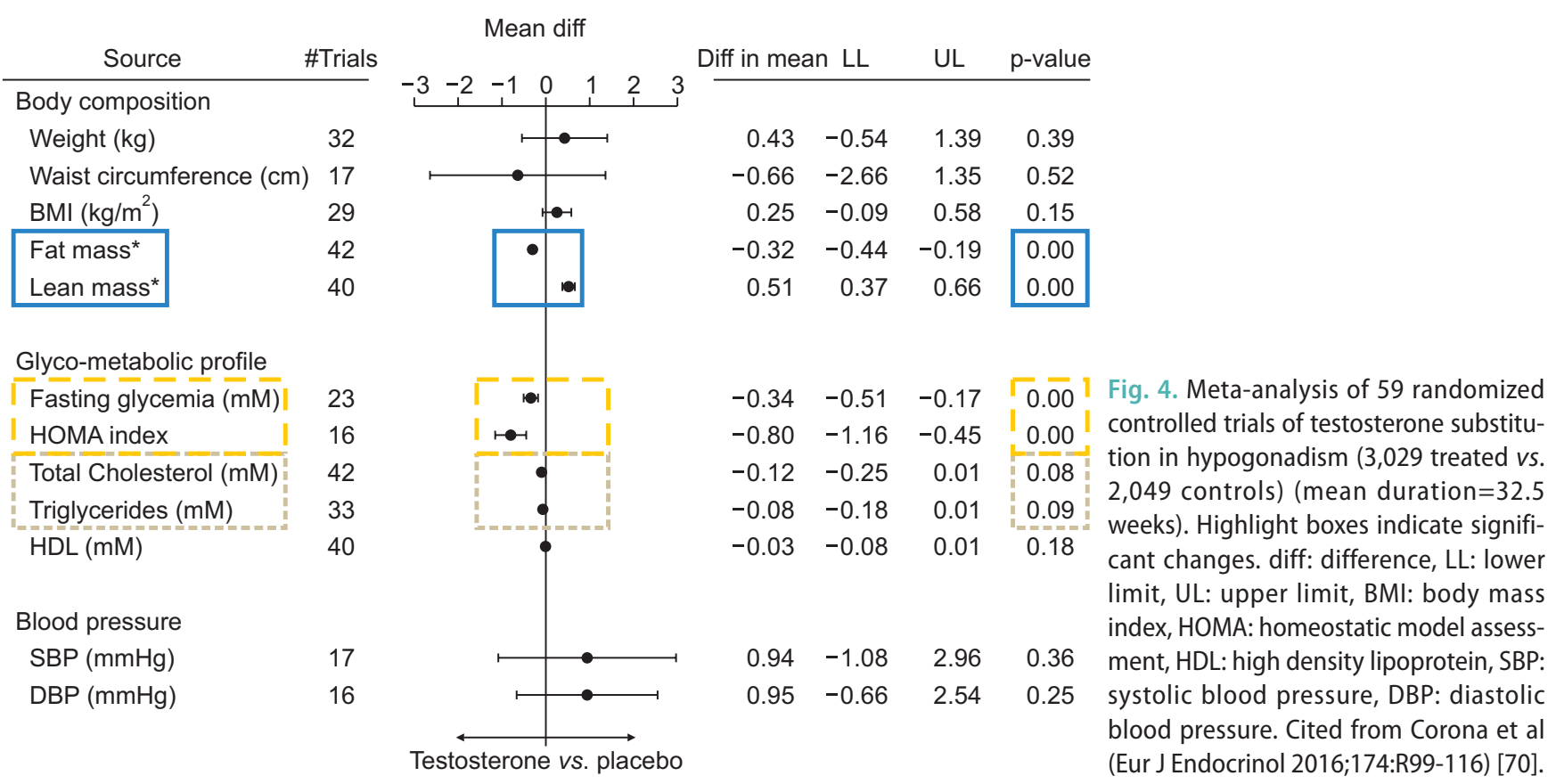


increased CV risk and evidence of a reduction in allcause mortality in men with cardiometabolic disease, such as T2DM and metabolic syndrome [64]. These findings suggest that men with $\mathrm{T} 2 \mathrm{DM}$ and metabolic syndrome are likely to see the greatest benefits from TRT and that these benefits might be underestimated when meta-analyses combine these men with younger cohorts.

\section{TESTOSTERONE THERAPY, CARDIOVASCULAR AND ALL-CAUSE MORTALITY IN TYPE 2 DIABETES}

Numerous long-term studies, and various reviews and meta-analyses, have provided evidence to support the association between HG and increased CV and allcause mortality. A systematic review and meta-analysis evaluating the association between endogenous testosterone and mortality concluded that low levels of endogenous testosterone are associated with an increased risk of all-cause and CV death in communitybased studies of men, with a reduction of 2.1 standard deviations in TT being associated with a $25 \%$ increase in mortality. However, most of the studies had issues with cohort selection and choice [20,21]. These studies suggest that taking no action, or not measuring testosterone at all, is likely to have severe implications for men with T2DM and low testosterone [71].

\section{MECHANISMS FOR POSSIBLE INCREASED CARDIOVASCULAR RISK}

Adverse CVD events associated with testosterone therapy may stem from a $6 \%$ increased rate of polycythaemia related to multiple mechanisms. The conversion of testosterone to oestradiol stimulates erythropoiesis in the bone marrow. Testosterone also stimulates the synthesis of erythropoetin in the kidney, subsequently erythropoiesis, and the testosterone-induced increase of hepatic transcription factors, resulting in a reduction hepcidin from increased iron usage. Supraphysiologic levels of testosterone observed with shortacting injections may amplify this effect as may the conversion of testosterone gels to DHT, via the action of 5- $\alpha$ reductase in skin. Increased DHT levels may be associated with an increased risk of fluid retention and thrombosis, resulting in hypertension and heart failure [72]. No studies, however, have demonstrated increase risk of deep vein thrombosis [73]. Studies with high doses of testosterone have described reduced levels of high density lipoprotein cholesterol and adiponectin [72].

\section{STUDIES SUGGESTING INCREASED CARDIOVASCULAR RISK}

A retrospective USA study [74] involved 8,709 men with a baseline TT of $\leq 10.4 \mathrm{nmol} / \mathrm{L}$ who were undergoing angiography. During a mean follow-up of 840 days, 681 of the 7,486 patients not receiving testosterone therapy died, 420 suffered MIs and 486 experienced strokes. Of the 1,223 patients receiving testosterone therapy, 67 died, 23 suffered MIs and 33 experienced strokes. Complex statistical analysis, using more than 50 covariates, concluded that there was a greater risk in the testosterone therapy group. However, there were concerns regarding the exclusion of 1,132 patients who experienced events because they were prescribed testosterone therapy after the event, when they should have been included in the untreated group, increasing the events by $70 \%$. There was also no data confirming a correct diagnosis of TDS before testosterone therapy and none on compliance. Furthermore, some patients did not continue testosterone therapy, and mean TT levels were at the lower end of normal, suggesting many were undetected. When challenged, the authors revised the number to 132 , but admitted that 104 women had been mistakenly included in the results.

A study analysing prescribing data in men treated with testosterone therapy [75], without records of blood results or symptoms, defined non-fatal coronary events as the major endpoint, assessed in the 12 months before and 3 months after therapy. However, the benefits of testosterone therapy take longer than this to appear and other studies have excluded the first 3 months treatment from analysis due to the likelihood of events relating to the pre-existing condition. Crucially, data on fatal CV events and all-cause mortality data was not collected, despite testosterone therapy in other studies having a major impact on mortality rather than event numbers. Twelve-month post-treatment data were collected but not presented. Prior to treatment, the event rates within the groups were strangely identical. There was a small increase in non-fatal cardiac events in men taking testosterone therapy, which was more marked in those with increased risk. Overall, events were lower 
than predicted from comparable research. The lack of mortality data demonstrates a failing to realise that a treatment that reduced mortality was likely to increase non-fatal events. In addition, the study design was not prospective, which casts doubts on the validity of retrospective assessment for the 12-month pre-treatment period.

\section{STUDIES SUGGESTING REDUCTION IN CARDIOVASCULAR EVENTS}

The various metabolic benefits in terms of improved insulin resistance, reduced fat mass, increased lean muscle mass, and reduction in inflammatory markers might be expected to translate into a reduction in CV risk. Inadequate therapy might leave the patient at increased risk of undertreated HG, such that trials need to be assessed in terms of adequate compliance and evidence of sustained treatment to therapeutic levels [47,76].

Two longitudinal studies have assessed long term mortality, exclusively in men with T2DM.

In a prospective study involving 587 men with T2DM [23], patients were followed-up for a mean of 5.81 years. Low testosterone was defined as TT $<10.4 \mathrm{nmol} / \mathrm{L}$. Fiftyeight men received testosterone therapy for at least 2 years. The mortality rates were $20 \%$ in the untreated group vs. 9.1\% in the untreated group, independent of comorbidities and therapies, and $8.6 \%$ in the treated group.

Another prospective study followed-up 857 men with

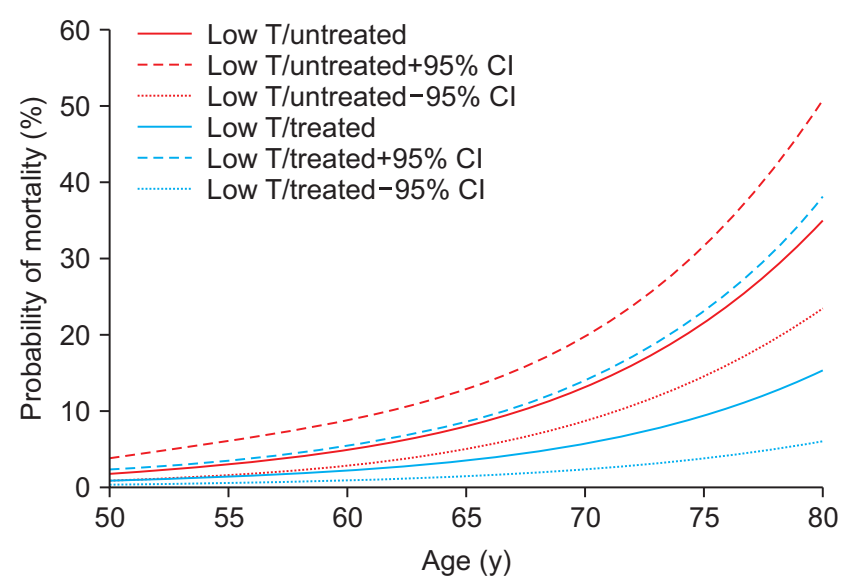

Fig. 5. Estimated mortality probability and $95 \%$ confidence intervals (Cls) from the fitted logistic regression: Men stratified by testosterone (T) replacement therapy. Data from Hackett et al (World J Diabetes 2017;8:104-11) [67].
T2DM for 4 years after baseline testosterone measurement [62]. Patients were randomised to either long acting TU or placebo. Results showed that low baseline TT and FT were associated with increased all-cause mortality. Testosterone therapy and the use of PDE5 inhibitors were independently associated with reduced all-cause mortality, with the greatest benefit from both treatments being seen in older men [62,67]. A major strength of this study was clear record of all testosterone doses administered and accurate recording of all medications, including PDE5 inhibitors (Fig. 5, 6).

These findings of reduced mortality in men taking PDE5 inhibitors is in close agreement with Anderson et al [77] who followed-up 5,956 men with T2DM over 6.9 years. A $31 \%$ reduction in all-cause mortality and $26 \%$ reduction in MI were reported with a low rate of PDE5 inhibitor prescribing at $22.8 \%$. Earlier safety data from licensing studies showed similar trends but mortality reduction was not a primary outcome and studies were powered to show safety and not benefit. Postulated mechanisms are postulated as protection against endothelial reperfusion injury, improved endothelial function and reduced systemic and pulmonary blood pressure [78]. Unfortunately, testosterone levels were not recorded in this study. Andersson et al [79] followed-up 43,415 men after first MI for 5 years and found significant reduction in all-cause and CV mortality and 30\% reduction in new diagnosis in heart failure and related admissions, in men prescribed PDE5 inhibitors. The benefits appeared dose related and were not seen with

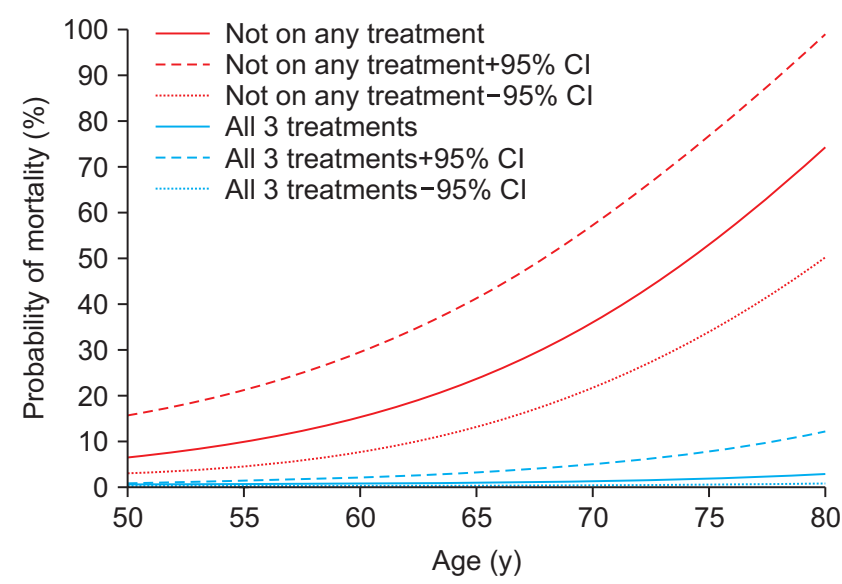

Fig. 6. Estimated mortality probability and 95\% confidence intervals (Cls) from fitted logistic regression: men on all or none of the treatments testosterone replacement therapy, phosphodiesterase type 5 inhibitor, or statin). Data from Hackett et al (World J Diabetes 2017;8:104-11) [67]. 
other ED therapies.

In a retrospective study involving 1,031 hypogonadal men, 372 of whom took $\mathrm{T}$ therapy, the cumulative mortality was $21 \%$ in the untreated group vs. $10 \%$ in the treated group. The greatest effect was observed in younger men and those with T2DM [80].

In a virtual controlled study, researchers examined electronic medical records between 1996 and 2011 to identify 5,695 men with a low initial TT level, a subsequent testosterone level, and up to 3 years of follow-up [81]. Testosterone levels were correlated with the use of testosterone supplementation. The primary outcomes were a composite of death, nonfatal MI, and stroke (MACE) and death alone. Testosterone supplementation in men with low testosterone levels was associated with a reduced incidence of MACE and death over 3 years compared with no or ineffective supplementation. The results suggest that the positive impact of testosterone therapy was mainly on mortality as opposed to the number of events, and the benefits were associated with the achievement of therapeutic levels of testosterone. There was no suggestion of increased risk with sustained higher serum levels.

Sharma et al [82] retrospectively evaluated 83,010 male veterans with documented low TT levels. The subjects were categorised into three groups: testosterone therapy with resulting normalisation of TT levels (group 1); testosterone therapy without normalisation of TT levels (group 2); and did not receive testosterone therapy (group 3). The all-cause mortality (hazard ratio [HR], 0.53; 95\% CI, 0.50-0.55), risk of MI (HR, 0.82; 95\% CI, 0.71-0.95), and stroke (HR, 0.70; 95\% CI, 0.51-0.96) were significantly lower in group 1 vs. group 2 ( $n=25,701$; median age, 66 years; mean follow-up, 4.6 years).

Wallis et al [83] reported a 5-year follow-up of 10,311 men on long term testosterone replacement compared with a 28,029-control group and found a decreased risk in all-cause mortality (HR, 0.67; 95\% CI, 0.62-0,73), CV events (HR, 0.84; 95\% CI, 0.72-0.98) and new cases of prostate cancer (HR, 0.60; 95\% CI, 0.45-0.80). There appeared to be slight increased risk of $\mathrm{CV}$ events in the first 6 months that could have been related to increased risk caused by low testosterone before patients reached therapeutic targets.

\section{CONCLUSIONS}

The low levels of testosterone frequently seen in men with T2DM are associated with increased comorbidity and mortality. Studies with testosterone therapy suggest significant benefits in sexual function, quality of life, glycaemic control, anaemia, bone density, fat, and lean muscle mass. Longitudinal studies on $\mathrm{CV}$ and allcause mortality have several logistic problems, related to potential increased mortality associated with inadequately treated patients and possible selection bias. Future studies need to address the impact of depression and especially PDE5 inhibitor use, due to the growing evidence that these drugs impact CV and all-cause morbidity and mortality. Men with T2DM usually require PDE5 inhibitors as well as testosterone therapy to improve sexual function by addressing the multiple comorbidities. Restricting therapy to men with classical HG is not supported by evidence. The results of lifestyle intervention as sole therapy for HG in T2DM are disappointing. The balance of evidence suggests that men with T2DM, metabolic syndrome and HG are likely to benefit from testosterone therapy combined with lifestyle intervention. Meta-analyses of RCTs, rather than providing clarification, have further confused the issue by including under-powered studies of inadequate duration, non-homogenous cohorts, multiple regimes, discontinued medication, and inbuilt bias in terms of studies included or excluded from analysis.

\section{Disclosure}

Dr. Geoffrey Hackett has acted as an occasional speaker for Bayer and Besins. These companies had no influence on this project.

\section{Author Contribution}

Research conception \& design: Hackett G. Data acquisition: Hackett G. Data analysis and interpretation: Hackett G. Drafting of the manuscript: Hackett G. Critical revision of the manuscript: Hackett G. Approval of final manuscript: Hackett G.

\section{REFERENCES}

1. Diabetes UK. More people than ever have diabetes. More people than ever are at risk of type 2 diabetes. If nothing changes, more than five million people will have diabetes in the UK by 
2025 [Internet]. London: Diabetes UK; c2017 [cited 2018 Apr 1]. Available from: https://www.diabetes.org.uk/Professionals/ Position-statements-reports/Statistics.

2. American Diabetes Association. Statistics about Diabetes [Internet]. Arlington (VA): American Diabetes Association; [cited 2018 Apr 1]. Available from: http://www.diabetes.org/ diabetes-basics/statistics/.

3. Hackett GI, Cole NS, Deshpande AA, Popple MD, Kennedy D, Wilkinson P. Biochemical hypogonadism in men with type 2 diabetes in primary care practice. Br J Diabetes Vasc Dis 2009;9:226-31.

4. Goodman N, Guay A, Dandona P, Dhindsa S, Faiman C, Cunningham GR, et al. American Association of Clinical Endocrinologists and American College of Endocrinology position statement on the association of testosterone and cardiovascular risk. Endocr Pract 2015;21:1066-73.

5. Bhasin S, Brito JP, Cunningham GR, Hayes FJ, Hodis HN, Matsumoto AM, et al. Testosterone therapy in men with hypogonadism: an endocrine society guideline. J Clin Endocrinol Metab 2018;103:1715-44.

6. Corona G, Rastrelli G, Maggi M. Diagnosis and treatment of late-onset hypogonadism: systematic review and meta-analysis of TRT outcomes. Best Pract Res Clin Endocrinol Metab 2013;27:557-79.

7. Kelly DM, Jones TH. Testosterone: a vascular hormone in health and disease. J Endocrinol 2013;217:R47-71.

8. Selvin E, Feinleib M, Zhang L, Rohrmann S, Rifai N, Nelson WG, et al. Androgens and diabetes in men: results from the Third National Health and Nutrition Examination Survey (NHANES III). Diabetes Care 2007;30:234-8.

9. Haffner SM, Shaten J, Stern MP, Smith GD, Kuller L. Low levels of sex hormone-binding globulin and testosterone predict the development of non-insulin-dependent diabetes mellitus in men. MRFIT research group. Multiple risk factor intervention trial. Am J Epidemiol 1996;143:889-97.

10. Ding EL, Song Y, Manson JE, Hunter DJ, Lee CC, Rifai N, et al. Sex hormone-binding globulin and risk of type 2 diabetes in women and men. N Engl J Med 2009;361:1152-63.

11. Corona G, Monami M, Rastrelli G, Aversa A, Tishova Y, Saad F, et al. Testosterone and metabolic syndrome: a meta-analysis study. J Sex Med 2011;8:272-83.

12. Stellato RK, Feldman HA, Hamdy O, Horton ES, McKinlay JB. Testosterone, sex hormone-binding globulin, and the development of type 2 diabetes in middle-aged men: prospective results from the Massachusetts male aging study. Diabetes Care 2000;23:490-4.

13. Oh JY, Barrett-Connor E, Wedick NM, Wingard DL; Rancho Bernardo Study. Endogenous sex hormones and the develop- ment of type 2 diabetes in older men and women: the Rancho Bernardo study. Diabetes Care 2002;25:55-60.

14. Laaksonen DE, Niskanen L, Punnonen K, Nyyssönen K, Tuomainen TP, Valkonen VP, et al. Testosterone and sex hormone-binding globulin predict the metabolic syndrome and diabetes in middle-aged men. Diabetes Care 2004;27:1036-41.

15. Vikan T, Schirmer H, Njølstad I, Svartberg J. Low testosterone and sex hormone-binding globulin levels and high estradiol levels are independent predictors of type 2 diabetes in men. Eur J Endocrinol 2010;162:747-54.

16. Lakshman KM, Bhasin S, Araujo AB. Sex hormone-binding globulin as an independent predictor of incident type 2 diabetes mellitus in men. J Gerontol A Biol Sci Med Sci 2010;65: 503-9.

17. Li C, Ford ES, Li B, Giles WH, Liu S. Association of testosterone and sex hormone-binding globulin with metabolic syndrome and insulin resistance in men. Diabetes Care 2010;33: 1618-24.

18. Antonio L, Wu FC, O’Neill TW, Pye SR, Carter EL, Finn JD, et al. Associations between sex steroids and the development of metabolic syndrome: a longitudinal study in European men. J Clin Endocrinol Metab 2015;100:1396-404.

19. Holmboe SA, Jensen TK, Linneberg A, Scheike T, Thuesen $\mathrm{BH}$, Skakkebaek NE, et al. Low testosterone: a risk marker rather than a risk factor for type 2 diabetes. J Clin Endocrinol M 2016;101:3180-90.

20. Araujo AB, Dixon JM, Suarez EA, Murad MH, Guey LT, Wittert GA. Clinical review: endogenous testosterone and mortality in men: a systematic review and meta-analysis. J Clin Endocrinol Metab 2011;96:3007-19.

21. Ruige JB, Mahmoud AM, De Bacquer D, Kaufman JM. Endogenous testosterone and cardiovascular disease in healthy men: a meta-analysis. Heart 2011;97:870-5.

22. Haring R, Völzke HV, Steveling A, Krebs A, Felix SB, Schöfl $\mathrm{C}$, et al. Low serum testosterone levels are associated with increased risk of mortality in a population-based cohort of men aged 20-79. Eur Heart J 2010;31:1494-501.

23. Muraleedharan V, Marsh H, Kapoor D, Channer KS, Jones $\mathrm{TH}$. Testosterone deficiency is associated with increased risk of mortality and testosterone replacement improves survival in men with type 2 diabetes. Eur J Endocrinol 2013;169:72533.

24. Yeap BB, Alfonso H, Chubb SA, Handelsman DJ, Hankey GJ, Almeida OP, et al. In older men an optimal plasma testosterone is associated with reduced all-cause mortality and higher dihydrotestosterone with reduced ischemic heart disease mortality, while estradiol levels do not predict mortality. J Clin Endocrinol Metab 2014;99:E9-18. 
25. Daka B, Langer RD, Larsson CA, Rosén T, Jansson PA, Råstam L, et al. Low concentrations of serum testosterone predict acute myocardial infarction in men with type 2 diabetes mellitus. BMC Endocr Disord 2015;15:35.

26. Hackett GI. Testosterone replacement therapy and mortality in older men. Drug Saf 2016;39:117-30.

27. Muraleedharan V, Jones TH. Testosterone and mortality. Clin Endocrinol (Oxf) 2014;81:477-87.

28. Oskui PM, French WJ, Herring MJ, Mayeda GS, Burstein S, Kloner RA. Testosterone and the cardiovascular system: a comprehensive review of the clinical literature. J Am Heart Assoc 2013;2:e000272.

29. Home P, Mant J, Diaz J, Turner C; Guideline Development Group. Management of type 2 diabetes: summary of updated NICE guidance. BMJ 2008;336:1306-8.

30. Bonora E, Formentini G, Calcaterra F, Lombardi S, Marini F, Zenari L, et al. HOMA-estimated insulin resistance is an independent predictor of cardiovascular disease in type 2 diabetic subjects: prospective data from the Verona diabetes complications study. Diabetes Care 2002;25:1135-41.

31. Stratton IM, Cull CA, Adler AI, Matthews DR, Neil HA, Holman RR. Additive effects of glycaemia and blood pressure exposure on risk of complications in type 2 diabetes: a prospective observational study (UKPDS 75). Diabetologia 2006; 49:1761-9.

32. Holman RR, Paul SK, Bethel MA, Matthews DR, Neil HA. 10year follow-up of intensive glucose control in type 2 diabetes. N Engl J Med 2008;359:1577-89.

33. Laaksonen DE, Niskanen L, Punnonen K, Nyyssönen K, Tuomainen TP, Valkonen VP, et al. The metabolic syndrome and smoking in relation to hypogonadism in middle-aged men: a prospective cohort study. J Clin Endocrinol Metab 2005;90: 712-9.

34. Tsai EC, Boyko EJ, Leonetti DL, Fujimoto WY. Low serum testosterone level as a predictor of increased visceral fat in Japanese-American men. Int J Obes Relat Metab Disord 2000;24:485-91.

35. Travison TG, Araujo AB. O’Donnell AB, Kupelian V, McKinlay JB. A population-level decline in serum testosterone levels in American men. J Clin Endocrinol Metab 2007;92:196-202.

36. Haring R, Ittermann T, Völzke H, Krebs A, Zygmunt M, Felix $\mathrm{SB}$, et al. Prevalence, incidence and risk factors of testosterone deficiency in a population-based cohort of men: results from the study of health in Pomerania. Aging Male 2010;13:247-57.

37. Kumagai H, Zempo-Miyaki A, Yoshikawa T, Tsujimoto T, Tanaka K, Maeda S. Lifestyle modification increases serum testosterone level and decrease central blood pressure in overweight and obese men. Endocr J 2015;62:423-30.
38. Gloy VL, Briel M, Bhatt DL, Kashyap SR, Schauer PR, Mingrone $\mathrm{G}$, et al. Bariatric surgery versus non-surgical treatment for obesity: a systematic review and meta-analysis of randomised controlled trials. BMJ 2013;347:f5934.

39. Rastrelli G, Carter EL, Ahern T, Finn JD, Antonio L, O’Neill TW, et al. Development of and recovery from secondary hypogonadism in aging men: prospective results from the EMAS. J Clin Endocrinol Metab 2015;100:3172-82.

40. Ng Tang Fui M, Hoermann R, Prendergast LA, Zajac JD, Grossmann M. Symptomatic response to testosterone treatment in dieting obese men with low testosterone levels in a randomized, placebo-controlled clinical trial. Int J Obes (Lond) 2017;41:420-26.

41. Ng Tang Fui M, Prendergast LA, Dupuis P, Raval M, Strauss BJ, Zajac JD, et al. Effects of testosterone treatment on body fat and lean mass in obese men on a hypocaloric diet: a randomised controlled trial. BMC Med 2016;14:153.

42. The T4DM [Internet]. Sydney: The T4DM; [cited 2018 Apr 1]. Available from: www.t4dm.org.au.

43. Kapoor D, Clarke S, Stanworth R, Channer KS, Jones TH. The effect of testosterone replacement therapy on adipocytokines and C-reactive protein in hypogonadal men with type 2 diabetes. Eur J Endocrinol 2007;156:595-602.

44. Kalinchenko SY, Tishova YA, Mskhalaya GJ, Gooren LJ, Giltay EJ, Saad F. Effects of testosterone supplementation on markers of the metabolic syndrome and inflammation in hypogonadal men with the metabolic syndrome: the doubleblinded placebo-controlled Moscow study. Clin Endocrinol (Oxf) 2010;73:602-12.

45. Jones TH, Arver S, Behre HM, Buvat J, Meuleman E, Moncada I, et al. Testosterone replacement in hypogonadal men with type 2 diabetes and/or metabolic syndrome (the TIMES2 study). Diabetes Care 2011;34:828-37.

46. Hackett G, Cole N, Bhartia M, Kennedy D, Raju J, Wilkinson P, et al. The response to testosterone undecanoate in men with type 2 diabetes is dependent on achieving threshold serum levels (the BLAST study). Int J Clin Pract 2014;68:203-15.

47. Dhindsa S, Ghanim H, Batra M, Kuhadiya ND, Abuaysheh S, Sandhu S, et al. Insulin resistance and inflammation in hypogonadotropic hypogonadism and their reduction after testosterone replacement in men with type 2 diabetes. Diabetes care 2016;39:82-91.

48. Francomano D, Lenzi A, Aversa A. Effects of five-year treatment with testosterone undecanoate on metabolic and hormonal parameters in ageing men with metabolic syndrome. Int J Endocrinol 2014;2014:527470.

49. Zitzmann M, Mattern A, Hanisch J, Gooren L, Jones H, Maggi M. IPASS: a study on the tolerability and effectiveness 
of injectable testosterone undecanoate for the treatment of male hypogonadism in a worldwide sample of 1,438 men. J Sex Med 2013;10:579-88.

50. Traish AM, Haider A, Doros G, Saad F. Long-term testosterone therapy in hypogonadal men ameliorate elements of the metabolic syndrome: an observational, long-term registry study. Int J Clin Pract 2014;68:314-29.

51. Gianatti EJ, Dupuis P, Hoermann R, Strauss BJ, Wentworth JM, Zajac JD, et al. Effect of testosterone treatment on glucose metabolism in men with type 2 diabetes: a randomized controlled trial. Diabetes Care 2014;37:2098-107.

52. Hackett GI. Erectile dysfunction, diabetes and cardiovascular risk. Br J Diabetes 2016;16:52-7.

53. Zitzmann M, Faber S, Nieschlag E. Association of specific symptoms and metabolic risks with serum testosterone in older men. J Clin Endocrinol Metab 2006;91:4335-43.

54. Buvat J, Montorsi F, Maggi M, Porst H, Kaipia A, Colson MH, et al. Hypogonadal men nonresponders to the PDE5 inhibitor tadalafil benefit from normalization of testosterone levels with a $1 \%$ hydroalcoholic testosterone gel in the treatment of erectile dysfunction (TADTEST study). J Sex Med 2011;8:28493.

55. Lowe G, Bahnson R. Non-invasive management of primary phosphodiesterase type 5 inhibitor failure in patients with erectile dysfunction. Ther Adv Urol 2009;1:235-42.

56. Hackett G, Cole N, Saghir A, Jones P, Strange RC, Ramachandran $S$, et al. Testosterone undecanoate improves sexual function in men with type 2 diabetes and severe hypogonadism: results from a 30-week randomized placebo-controlled study. BJU Int 2016;118:804-13.

57. Hackett G, Cole N, Bhartia M, Kennedy D, Raju J, Wilkinson P. Testosterone replacement therapy with long-acting testosterone undecanoate improves sexual function and quality-oflife parameters vs. placebo in a population of men with type 2 diabetes. J Sex Med 2013;10:1612-27.

58. de Groot M, Anderson R, Freedland KE, Clouse RE, Lustman PJ. Association of depression and diabetes complications: a meta-analysis. Psychosom Med 2001;63:619-30.

59. Snyder PJ, Bhasin S, Cunningham GR, Matsumoto AM, Stephens-Shields AJ, Cauley JA, et al. Effects of testosterone treatment in older men. N Engl J Med 2016;374:611-24.

60. Spitzer M, Bhasin S, Travison TG, Davda MN, Stroh H, Basaria S. Sildenafil increases serum testosterone levels by a direct action on the testes. Andrology 2013;1:913-8.

61. Hackett G. Should PDE5Is be prescribed routinely for all men with newly diagnosed type 2 diabetes? Br J Diabetes Vasc Dis 2015;15:184-6.

62. Hackett G, Heald AH, Sinclair A, Jones PW, Strange RC,
Ramachandran S. Serum testosterone, testosterone replacement therapy and all- cause mortality in men with type 2 diabetes: retrospective consideration of the impact of PDE5 inhibitors and statins. Int J Clin Pract 2016;70:244-53.

63. Grossmann M, Hoermann R, Wittert G, Yeap BB. Effects of testosterone treatment on glucose metabolism and symptoms in men with type 2 diabetes and the metabolic syndrome: a systematic review and meta-analysis of randomized controlled clinical trials. Clin Endocrinol (Oxf) 2015;83:344-51.

64. Corona G, Maseroli E, Rastrelli G, Isidori AM, Sforza A, Mannucci E, et al. Cardiovascular risk associated with testosterone-boosting medications: a systematic review and metaanalysis. Expert Opin Drug Saf 2014;13:1327-51.

65. Corona G, Rastrelli G, Morgentaler A, Sforza A, Mannucci E, Maggi M. Meta-analysis of results of testosterone therapy on sexual function based on international index of erectile function scores. Eur Urol 2017;72:1000-11.

66. Borst SE, Yarrow JF. Injection of testosterone may be safer and more effective than transdermal administration for combating loss of muscle and bone in older men. Am J Physiol Endocrinol Metab 2015;308:E1035-42.

67. Hackett G, Jones PW, Strange RC, Ramachandran S. Statin, testosterone and phosphodiesterase 5-inhibitor treatments and age related mortality in diabetes. World J Diabetes 2017; 8:104-11.

68. Huo S, Scialli AR, McGarvey S, Hill E, Tügertimur B, Hogenmiller A, et al. Treatment of men for "low testosterone": a systematic review. PLoS One 2016;11:e0162480.

69. Ponce OJ, Spencer-Bonilla G, Alvarez-Villalobos N, Serrano V, Singh-Ospina N, Rodriguez-Gutierrez R, et al. The efficacy and adverse events of testosterone replacement therapy in hypogonadal men: a systematic review and meta-analysis of randomized, placebo-controlled trials. J Clin Endocrinol Metab 2018. doi: 10.1210/jc.2018-00404 [Epub].

70. Corona G, Giagulli VA, Maseroli E, Vignozzi L, Aversa A, Zitzmann M, et al. Therapy of endocrine disease: testosterone supplementation and body composition: results from a metaanalysis study. Eur J Endocrinol 2016;174:R99-116.

71. Xu L, Freeman G, Cowling BJ, Schooling CM. Testosterone therapy and cardiovascular events among men: a systematic review and meta-analysis of placebo-controlled randomized trials. BMC Med 2013;11:108.

72. Doğan BA, Karakılıç E, Tuna MM, Arduç A, Berker D, Güler S. Effect of androgen replacement therapy on atherosclerotic risk markers in young-to-middle-aged men with idiopathic hypogonadotropic hypogonadism. Clin Endocrinol (Oxf) 2015;82:422-8.

73. Baillargeon J, Urban RJ, Ottenbacher KJ, Pierson KS, Good- 
win JS. Trends in androgen prescribing in the United States, 2001 to 2011. JAMA Intern Med 2013;173:1465-6.

74. Vigen R, O’Donnell CI, Barón AE, Grunwald GK, Maddox TM, Bradley SM, et al. Association of testosterone therapy with mortality, myocardial infarction, and stroke in men with low testosterone levels. JAMA 2013;310:1829-36.

75. Finkle WD, Greenland S, Ridgeway GK, Adams JL, Frasco MA, Cook MB, et al. Increased risk of non-fatal myocardial infarction following testosterone therapy prescription in men. PLoS One 2014;9:e85805.

76. Kloner RA, Carson C 3rd, Dobs A, Kopecky S, Mohler ER 3rd. Testosterone and cardiovascular disease. J Am Coll Cardiol 2016;67:545-57.

77. Anderson SG, Hutchings DC, Woodward M, Rahimi K, Rutter MK, Kirby M, et al. Phosphodiesterase type-5 inhibitor use in type 2 diabetes is associated with a reduction in allcause mortality. Heart 2016;102:1750-6.

78. Pofi R, Gianfrilli D, Badagliacca R, Di Dato C, Venneri MA, Giannetta E. Everything you ever wanted to know about phosphodiesterase 5 inhibitors and the heart (but never dared ask): how do they work? J Endocrinol Invest 2016;39:131-42.
79. Andersson DP, Trolle Lagerros Y, Grotta A, Bellocco R, Lehtihet M, Holzmann MJ. Association between treatment for erectile dysfunction and death or cardiovascular outcomes after myocardial infarction. Heart 2017;103:1264-70.

80. Shores MM, Smith NL, Forsberg CW, Anawalt BD, Matsumoto AM. Testosterone treatment and mortality in men with low testosterone levels. J Clin Endocrinol Metab 2012;97:2050-8.

81. Anderson JL, May HT, Lappé DL, Bair T, Le V, Carlquist JF, et al. Impact of testosterone replacement therapy on myocardial infarction, stroke, and death in men with low testosterone concentrations in an integrated health care system. Am J Cardiol 2016;117:794-9.

82. Sharma R, Oni OA, Gupta K, Chen G, Sharma M, Dawn B, et al. Normalization of testosterone level is associated with reduced incidence of myocardial infarction and mortality in men. Eur Heart J 2015;36:2706-15.

83. Wallis CJ, Lo K, Lee Y, Krakowsky Y, Garbens A, Satkunasivam R, et al. Survival and cardiovascular events in men treated with testosterone replacement therapy: an intention-to-treat observational cohort study. Lancet Diabetes Endocrinol 2016; 4:498-506. 